\title{
PLA/Kenaf/APP biocomposites: effect of alkali treatment and ammonium polyphosphate (APP) on dynamic mechanical and morphological properties
}

\begin{abstract}
Kenaf-filled polylactic acid (PLA) biocomposites were prepared using dry blending, twin screw extrusion and compression molding. PLA was blended with raw and alkali treated kenaf, polyethylene glycol and ammonium polyphosphate (APP). Dynamic mechanical properties of biocomposites were investigated by dynamic mechanical analysis. Storage modulus of composites decreased, while magnitude of damping peaks increased with increase in APP content. The $\mathrm{T} g$ of composites shifted to lower values with APP addition. Alkali treatment improved interfacial adhesion between PLA and kenaf. SEM analysis indicates good dispersion of APP in PLA matrix, however interfacial adhesion between PLA and matrix decreased with increasing APP content.
\end{abstract}

Keyword: Biocomposite; DMA; Kenaf fiber; PLA; SEM 